\title{
PENGARUH JAMU DENGAN Tribulus terrestris TERHADAP KUALITAS SPERMA TIKUS WISTAR JANTAN (Rattus norvegicus)
}

\author{
${ }^{1}$ Delano Pelealu \\ ${ }^{2}$ Lydia Tendean \\ ${ }^{2}$ Benny Wantouw
}

\author{
${ }^{1}$ Kandidat Skripsi Fakultas Kedokteran Universitas Sam Ratulangi Manado \\ ${ }^{2}$ Bagian Biologi Fakultas Kedokteran Universitas Sam Ratulangi Manado \\ Email:delanopelealu@gmail.com
}

\begin{abstract}
It is known that Tribulus terrestris can improve sperm quality. One of the Indonesian traditional medicine, jamu, contains this Tribulus terrestris. This study aimed to investigate the effect of jamu containing Tribulus terrestris on sperm quality which consisted of concentration, motility, and morphology of spermatozoa of male wistar rats (Rattus norvegicus). This was an experimental study. Nine male wistar rats were randomly divided into 3 groups of 3 rats each: Group $\mathrm{P}_{0}$ (control), group $\mathrm{P}_{1}$ (given $5 \mathrm{mg}$ of Tribulus terrestris), and group $\mathrm{P}_{2}$ (given $10 \mathrm{mg}$ of Tribulus terrestris). This study was conducted for 52 days. The results showed that the spermatozoa concentration of $\mathrm{P}_{1}$ was $49 \times 10^{6} \mathrm{sperm} / \mathrm{ml}$ suspension and of $\mathrm{P}_{2} 53 \times 10^{6} \mathrm{sperm} / \mathrm{ml}$ suspension; both were lower than of $\mathrm{P}_{0}\left(59 \times 10^{6} \mathrm{sperm} / \mathrm{ml}\right.$ suspension). The sperm motility category $(A+B)$ of $P_{1}$ was $33 \%$ and of $P_{2}(37 \%)$; both were lower than of $\mathrm{P}_{0}(45 \%)$. The motility category A was not found in $\mathrm{P}_{1}$ and $\mathrm{P}_{2}$. The percentage of spermatozoa with normal morphology of $\mathrm{P}_{1}$ was $45 \%$ and the abnormal ones was $55 \%$, meanwhile in $\mathrm{P}_{2}$ there was $49 \%$ of normal sperm morphology and $51 \%$ of abnormal morphology. Conclusion: Jamu containing Tribulus terrestris had no effect in improvement of the sperm quality.
\end{abstract}

Keywords: jamu, Tribulus terrestris, sperm quality

\begin{abstract}
Abstrak: Tribulus terrestris dikenal sebagai bahan yang dapat memperbaiki kualitas sperma. Salah satu jenis jamu yang diproduksi di Indonesia mengandung Tribulus terrestris Penelitian ini bertujuan untuk mengetahui pengaruh jamu dengan Tribulus terrestris terhadap konsentrasi, motilitas, dan morfologi spermatozoa tikus wistar jantan (Rattus norvegicus). Penelitian ini menggunakan metode eksperimental. Sampel 9 ekor tikus wistar jantan (Rattus norvegicus) dibagi menjadi 3 kelompok yakni, kelompok $\mathrm{P}_{0}$ (kontrol); kelompok $\mathrm{P}_{1}$ (pemberian Tribulus terrestris $5 \mathrm{mg}$ ); dan kelompok $\mathrm{P}_{2}$ (pemberian Tribulus terrestris $10 \mathrm{mg}$ ). Penelitian dilakukan selama 52 hari. Hasil penelitian menunjukkan bahwa konsentrasi spermatozoa $\mathrm{P}_{1} 49 \times 10^{6}$ sperma/ml suspensi dan $\mathrm{P}_{2} 53 \times 10^{6}$ sperma/ml suspensi lebih rendah dibandingkan $\mathrm{P}_{0} 59 \times 10^{6}$ sperma/ml suspensi. Motilitas spermatozoa kategori $\mathrm{A}+\mathrm{B}$ pada $\mathrm{P}_{1}$ (33\%) dan $\mathrm{P}_{2}$ (37\%) lebih rendah dibandingkan pada $\mathrm{P}_{0}$ (45\%). Tidak ditemukan motilitas kategori A pada $\mathrm{P}_{1}$ dan $\mathrm{P}_{2}$. Morfologi spermatozoa normal pada $\mathrm{P}_{1}$ sebesar $45 \%$ dan abnormal $55 \%$. $\mathrm{P}_{2}$ memiliki morfologi spermatozoa normal sebesar $49 \%$ dan abnormal $51 \%$. Simpulan: Pemberian jamu dengan Tribulus terrestris tidak meningkatkan kualitas sperma yang mencakup konsentrasi, motilitas, dan morfologi spermatozoa.
\end{abstract}

Kata kunci: jamu, Tribulus terrestris, kualitas sperma

Jamu merupakan obat herbal tradisional yang telah digunakan selama berabad-abad oleh masyarakat Indonesia untuk menjaga kesehatan dan mengobati penyakit. ${ }^{1}$ Dari segi ekonomi, jamu dapat dijangkau oleh semua kalangan masyarakat karena 
harganya relatif murah dibandingkan obatobat modern. ${ }^{2}$ Salah satu perusahaan produsen jamu di Indonesia membuat produk jamu dengan kandungan Tribulus terrestris dan disebutkan bermanfaat dalam mengatasi gangguan kesuburan pria dan meningkatkan kualitas sperma.

Tribulus terrestris merupakan tanaman yang hidup di daerah beriklim tropis seperti Eropa, Asia Selatan, Afrika, dan Australia. ${ }^{3}$ Tribulus terrestris telah lama digunakan oleh masyarakat China dan India sebagai obat tradisional untuk mengobati berbagai penyakit, seperti gangguan pada traktus urinarius, kardiovaskuler, dan gastrointestinal., ${ }^{4,5}$ Ekstrak Tribulus terrestris yaitu protodioscin, merupakan saponin yang dapat meningkatkan kadar hormon testosteron, luteinizing hormone (LH), dehydroepiandrosterone (DHEA), dihydrotestosterone (DHT) dan dehydroepiandrosterone sulphate. ${ }^{6-8}$ Hormon testosteron merupakan hormon steroid yang diproduksi di testis dan berfungsi untuk perkembangan karakteristik seks sekunder pria seperti pertumbuhan rambut di wajah dan badan, pertumbuhan otot, dan produksi sperma. ${ }^{9}$

Beberapa penelitian melaporkan pemberian ekstrak Tribulus terrestris sebagai afrodisiak. ${ }^{10-12}$ Penelitian lainnya menyebutkan ekstrak Tribulus terrestris dapat meningkatkan performa seksual dan massa otot pada pria. ${ }^{13,14}$ Penggunaan Tribulus terrestris juga berpengaruh terhadap spermatogenesis. ${ }^{15}$

Penelitian pada tikus dilaporkan terjadi peningkatan spermatosit primer, konsentrasi, dan morfologi spermatozoa pada kelompok tikus yang diberi ekstrak Tribulus terrestris dibandingkan dengan kelompok kontrol. ${ }^{16}$

Keberhasilan sperma untuk membuahi ovum ditentukan oleh beberapa faktor, diantaranya ialah kualitas sperma yang terdiri dari konsentrasi, motilitas, dan morfologi spermatozoa. Pemberian jamu dengan Tribulus terrestris diharapkan dapat berpengaruh terhadap kualitas sperma tikus wistar jantan (Rattus norvegicus).

\section{METODE PENELITIAN}

Penelitian ini menggunakan metode eksperimental. Penelitian dilakukan di Laboratorium Biologi Fakultas Kedokteran Universitas Sam Ratulangi Manado dengan rentang waktu sekitar Oktober - Desember 2014.

Sampel yang digunakan 9 ekor tikus wistar jantan (Rattus norvegicus) dengan kriteria inklusi yaitu tikus wistar jantan (Rattus norvegicus) usia 5-6 bulan dengan berat badan 200 g. Kriteria eksklusi yaitu tikus wistar tampak sakit, tidak bergerak secara aktif, dan yang mati dalam penelitian.

Sampel dibagi menjadi 3 kelompok dan masing-masing kelompok terdiri dari 3 ekor tikus. Kelompok $\mathrm{P}_{0}$ merupakan kelompok kontrol; kelompok $\mathrm{P}_{1}$ merupakan kelompok perlakuan dengan pemberian Tribulus terrestris $5 \mathrm{mg}$; dan kelompok $\mathrm{P}_{2}$ merupakan kelompok perlakuan dengan pemberian Tribulus terrestris $10 \mathrm{mg}$.

\section{HASIL PENELITIAN \\ Konsentrasi Spermatozoa}

Pada Tabel 1 dapat dilihat bahwa rerata konsentrasi spermatozoa kelompok $\mathrm{P}_{1}$ $49 \times 10^{6} \mathrm{sperma} / \mathrm{ml}$ suspensi, dan kelompok $\mathrm{P}_{2}$ sebesar $53 \times 10^{6}$ sperma/ml suspensi.

Tabel 1. Hasil penghitungan rerata konsentrasi spermatozoa tikus wistar setelah pemberian jamu dengan Tribulus terrestris selama 52 hari

\begin{tabular}{cc}
\hline Kelompok & Konsentrasi Spermatozoa (x 106) \\
\hline $\mathrm{P}_{0}$ & 59 \\
$\mathrm{P}_{1}$ & 49 \\
$\mathrm{P}_{2}$ & 53
\end{tabular}

Keterangan: Kelompok $\mathrm{P}_{0}$, kontrol; Kelompok $\mathrm{P}_{1}$, pemberian Tribulus terrestris $5 \mathrm{mg}$; Kelompok $\mathrm{P}_{2}$, pemberian Tribulus terrestris $10 \mathrm{mg}$.

\section{Motilitas spermatozoa}

Pada Tabel 2 dapat dilihat bahwa kelompok $\mathrm{P}_{1}$ menunjukkan motilitas kategori A 0\% yang tidak berbeda dengan kelompok $\mathrm{P}_{2}$. Kelompok $\mathrm{P}_{1}$ memiliki 
motilitas spermatozoa kategori B sebanyak 33\% dan motilitas spermatozoa kategori B pada kelompok $\mathrm{P}_{2}$ sebanyak $37 \%$. Tabel di atas menunjukkan motilitas spermatozoa kategori $\mathrm{C}$ lebih tinggi dibandingkan motilitas spermatozoa kategori $\mathrm{A}$ dan $\mathrm{B}$ pada kelompok $\mathrm{P}_{0}, \mathrm{P}_{1}, \mathrm{P}_{2}$.

Tabel 2. Hasil penghitungan rata-rata motilitas spermatozoa tikus wistar setelah pemberian jamu dengan Tribulus terrestris selama 52 hari

\begin{tabular}{ccccc}
\hline Kelompok & \multicolumn{4}{c}{ Motilitas Spematozoa $(\%)$} \\
& Kategori A & Kategori B & Kategori C & A+B \\
\hline$P_{0}$ & 21 & 24 & 55 & 45 \\
$P_{1}$ & 0 & 33 & 67 & 33 \\
$P_{2}$ & 0 & 37 & 63 & 37 \\
\hline
\end{tabular}

Keterangan: Kelompok $\mathrm{P}_{0}$, kontrol; Kelompok $\mathrm{P}_{1}$, pemberian Tribulus terrestris 5 mg; Kelompok $\mathrm{P}_{2}$, pemberian Tribulus terrestris $10 \mathrm{mg}$.

\section{Morfologi spermatozoa}

Tabel 3 memperlihatkan kelompok $\mathrm{P}_{1}$ memiliki morfologi spermatozoa normal sebanyak $45 \%$ dan yang abnormal sebanyak 55\%. Kelompok $\mathrm{P}_{2}$ memiliki morfologi spermatozoa normal sebanyak 49\% dan yang abnormal sebanyak 51\%.

Tabel 3. Hasil penghitungan rata-rata morfologi spermatozoa tikus wistar setelah pemberian jamu dengan Tribulus terrestris selama 52 hari

\begin{tabular}{ccc}
\hline \multirow{2}{*}{ Kelompok } & \multicolumn{2}{c}{ Morfologi Spermatozoa (\%) } \\
Normal & Abnormal \\
\hline $\mathrm{P}_{0}$ & 57 & 43 \\
$\mathrm{P}_{1}$ & 45 & 55 \\
$\mathrm{P}_{2}$ & 49 & 51 \\
\hline
\end{tabular}

Keterangan: Kelompok $\mathrm{P}_{0}$, kontrol; Kelompok $\mathrm{P}_{1}$, pemberian Tribulus terrestris 5 mg; Kelompok $\mathrm{P}_{2}$, pemberian Tribulus terrestris $10 \mathrm{mg}$.

\section{BAHASAN}

Tabel 1 mengenai penghitungan rerata konsentrasi spermatozoa menunjukkan bahwa pemberian jamu dengan Tribulus terrestris tidak berpengaruh dalam meningkatkan konsentrasi spermatozoa. Berdasarkan teori, Tribulus terrestris meningkatkan hormon testosteron yang berperan dalam spermatogenesis. Hal ini sejalan dengan penelitian yang dilakukan Karimi, ${ }^{16}$ yakni pemberian variasi dosis ekstrak Tribulus terrestris pada tikus terbukti meningkatkan pembentukan spermatosit primer sehingga terjadi peningkatan konsentrasi spermatozoa. Pada penelitian ini, hasil yang ditemukan yakni rerata konsentrasi spermatozoa pada kelompok $\mathrm{P}_{1}$ dan $\mathrm{P}_{2}$ termasuk dalam kategori oligozoospermia karena berada di bawah nilai normal yaitu $58 \times 10^{6}$ sperma/ml suspensi.

Pada Tabel 2 mengenai penghitungan motilitas spermatozoa didapatkan bahwa kelompok $\mathrm{P}_{1}$ dan $\mathrm{P}_{2}$ tidak memiliki motilitas kategori A (bergerak progresif). Pada kelompok $\mathrm{P}_{1}$ jumlah kategori $\mathrm{A}$ dan $\mathrm{B}$ $33 \%$, dan pada kelompok $\mathrm{P}_{2}$ jumlah kategori A dan B 37\%. Hal ini berarti motilitas spermatozoa kelompok $\mathrm{P}_{1}$ dan $\mathrm{P}_{2}$ berada di bawah batas normal (kategori $\mathrm{A}+$ $\mathrm{B}=40 \%$ ). Pada kelompok $\mathrm{P}_{0}$ ditemukan adanya motilitas kategori A $21 \%$ dan kategori B 24\% dengan jumlah kategori A dan B sebesar 45\% (normal). Berdasarkan penelitian yang dilakukan oleh Al-Rubii et al. pemberian Tribulus terrestris pada kelinci dapat meningkatkan motilitas spermatozoa. Hal ini dikarenakan Tribulus terrestris memiliki efek antioksidan yang mencegah kerusakan spermatozoa. ${ }^{19}$ Pada penelitian ini ditemukan terjadi penurunan motilitas spermatozoa pada kedua kelompok tikus wistar yang diberi jamu dengan Tribulus terrestris.

Pada Tabel 3 mengenai morfologi spermatozoa memperlihatkan bahwa kelompok $\mathrm{P}_{1}$ dan $\mathrm{P}_{2}$ memiliki morfologi spermatozoa abnormal yang lebih tinggi dibanding morfologi spermatozoa normal. Kelompok $\mathrm{P}_{0}$ memiliki morfologi spermatozoa normal sebanyak 57\% dan morfologi spermatozoa abnormal sebanyak $43 \%$. Hal ini berarti kelompok $\mathrm{P}_{0}$ memiliki morfologi spermatozoa normal yang lebih 
tinggi dibandingkan morfologi spermatozoa abnormal.

Keseluruhan hasil di atas, yakni mengenai konsentrasi, motilitas, dan morfologi spermatozoa, menunjukkan adanya ketidaksesuaian dengan teori serta penelitian dari beberapa peneliti sebelumnya. Terjadinya ketidaksesuaian ini mungkin disebabkan antara lain oleh:

1. Jumlah sampel sedikit (9 ekor tikus wistar) dikarenakan oleh waktu yang dialokasikan terlalu singkat dan keterbatasan penyediaan sampel.

2. Tikus wistar yang dipakai dalam penelitian ini berusia 5-6 bulan dimana kemungkinan pada usia tersebut proses spermatogenesis sudah mulai menurun.

3. Tribulus terrestris yang terkandung pada produk jamu yang diteliti memiliki kualitas yang kurang baik dibandingkan Tribulus terrestris yang terkandung di dalam obat dan suplemen yang telah terbukti dapat meningkatkan kualitas sperma.

4. Pada produk jamu, selain mengandung Tribulus terrestris juga terdapat bahan herbal lainnya yang kemungkinan dapat menurunkan efek Tribulus terrestris bahkan justru dapat memberi efek toksik pada sperma.

5. Penelitian-penelitian sebelumnya mengenai efek Tribulus terrestris terhadap kualitas sperma menggunakan sediaan Tribulus terrestris murni, sedangkan pada penelitian ini menggunakan sediaan Tribulus terrestris dengan campuran bahan herbal lainnya.

\section{SIMPULAN}

Berdasarkan hasil penelitian ini dapat disimpulkan bahwa pemberian jamu dengan Tribulus terrestris tidak berpengaruh untuk meningkatkan kualitas sperma yang mencakup konsentrasi, motilitas, dan morfologi spermatozoa.

\section{SARAN}

Bagi peneliti selanjutnya disarankan agar jumlah sampel ditambah dengan waktu penelitian yang diperpanjang. Selain itu, perlu dilakukan pemeriksaan patologi anatomi untuk melihat proses spermatogenesis dalam jaringan testis

Juga perlu diteliti pengaruh bahan herbal lainnya dalam jamu dengan Tribulus terrestris terhadap spermatogenesis.

\section{DAFTAR PUSTAKA}

1. Torri MC. Knowledge and risk perceptions of traditional jamu medicine among urban consumers. European Journal of Medicinal Plants. 2013;3(1):25-39.

2. Riswan S, Sangat-Roemantyo H. Jamu as traditional medicine in Java, Indonesia. South Pacific Study. 2002;23 [cited 2014 Oct 12]. Available from: http://cpi.kagoshimau.ac.jp/publications /southpacificstudies/sps/sps23-

1/SouthPacificStudies23\%281\%29pp110.pdf

3. Samy MN, Bishr MM, Ahmed AA, Sayed HM, Kamel MS. Journal of pharmacognosy and phytochemistry. 2013;1 [cited 2014 Oct 12]. Available from:

http://www.phytojournal.com/vol1Issue 5/Issue_jan_2013/4.1.pdf

4. Mohd J, Akhtar AJ, Abuzer A, Javed A, Ali M, Ennus T. Pharmacological scientific evidence for the promise of Tribulus terrestris. IRJP. 2012;3(5) [cited 2014 Oct 12]. Available from: http://www.irjponline.com/admin/php/u ploads/1133_pdf.

5. Shreesh K, Ojha, Nandave M, Arora S, Narang R, Dinda AK, et al. Chronic administration of Tribulus terrestris Linn. extract improves cardiac function and attenuates myocardial infarction in rats. International Journal of Pharmacology. 2008;4:1-10.

6. Adimoelja A, Adaikan PG. Protodioscin from herbal plant Tribulus terrestris L. improves male sexual functions possibly via DHEA. International Journal of Impotence Research. 1997;9(1):S64.

7. Hussain AA, Mohammed AA, Ibrahim HH, Abbas AH. Study the biological activities of Tribulus terrestris extract. World Academy of Science, Engineering and Technology, 2009; p. 57.

8. Moghaddam MHG, Khalili M, Maleki M, Abadi MEA. The effect of oral feeding 
of Tribulus terrestris L. on sex hormone and gonadotropin levels in addicted male rats. Int J Fertil Steril. 2013;7(1): 57-62.

9. Arthur GC. Fisiologi manusia dan mekanisme penyakit. Jakarta: EGC, 2012; p. 731-32.

10. Gauthaman K, Adaikan PG, Prasad RN. Aphrodisiac properties of Tribulus terrestris extract (Protodioscin) in normal and castrated rats. Life Sci. 2002;71:1385-96.

11. Singh S, Nair V, Gupta YK. Evaluation of the aphrodisiac activity of Tribulus terrestris Linn. in sexually sluggish male albino rats. J Pharmacol Pharmacother. 2012; 3(1):43-7.

12. Kavitha $P$, Subramanian $P$. Effect of Tribulus terrestris on monosex production in Poecilia latipinna. Current Science. 2011;101(1).

13. Brown GA, Vukovich MD, Reifenrath
TA, Parsons KA, Sharp RL, King

DS. Effects of anabolic precursors on serum testosterone concentration and adaptations to resistance training in young men. Int $\mathrm{J}$ Sport Nutr Exer Metabol. 2000;10:340-59.

14. Milasius K, Pečiukonienè M, Dadelienè R, Skernevičius J. Efficacy of the Tribulus food supplement used by athletes. Acta Medica Lituanica. 2010; 17(1-2):65-70.

15. Gautaman K, Ganesan AP. The hormonal effects of Tribulus terrestris and its role in the management of erectile dysfunction: An evaluation using primates, rabbits and rat. Phytomedicine. 2008;15:44-54.

16. Karimi JH, Malekzadeh S, Hoshmand F. The effect of the Tribulus terrestris extract on spermatogenesis in the rat. Journal of Jahrom University of Medical Sciences. 2012;9. 